\title{
Genomic meta-analysis of growth factor and integrin pathways in chronic kidney transplant injury
}

Amrita Dosanjh, Elizabeth Robison, Tony Mondala, Steven R Head, Daniel R Salomon and Sunil M Kurian*

\begin{abstract}
Background: Chronic Allograft Nephropathy (CAN) is a clinical entity of progressive kidney transplant injury. The defining histology is tubular atrophy with interstitial fibrosis (IFTA). Using a meta-analysis of microarrays from 84 kidney transplant biopsies, we revealed growth factor and integrin adhesion molecule pathways differentially expressed and correlated with histological progression. A bioinformatics approach mining independent datasets leverages new and existing data to identify correlative changes in integrin and growth factor signaling pathways.

Results: Analysis of CAN/IFTA Banff grades showed that hepatocyte growth factor (HGF), and epidermal growth factor (EGF) pathways are significantly differentially expressed in all classes of CAN/IFTA. MAPK-dependent pathways were also significant. However, the TGF $\beta$ pathways, albeit present, failed to differentiate CAN/IFTA progression. The integrin subunits $\beta 8, a v, a \mu$ and $\beta 5$ are differentially expressed, but $\beta 1, \beta 6$ and a6 specifically correlate with progression of chronic injury. Results were validated using our published proteomic profiling of CAN/ IFTA.
\end{abstract}

Conclusions: CAN/IFTA with chronic kidney injury is characterized by expression of distinct growth factors and specific integrin adhesion molecules as well as their canonical signaling pathways. Drug target mapping suggests several novel candidates for the next generation of therapeutics to prevent or treat progressive transplant dysfunction with interstitial fibrosis.

Keywords: Chronic rejection, NA Microarrays, Genomics, Growth factors, Integrins, Proteomics, Meta-analysis, Chronic Allograft Nephropathy /Tubular atrophy with interstitial fibrosis (CAN/IFTA), Kidney transplantation

\section{Background}

Chronic Allograft Nephropathy (CAN) is defined as a clinical entity by chronic kidney injury leading to progressive loss of kidney transplant function in the absence of another known cause. In histological terms, the findings on a biopsy that match this clinical presentation are interstitial fibrosis and tubular atrophy (IFTA) based on the Banff '05 classification [1]. We will refer to this entity as CAN/IFTA to respect both the clinical and pathological definitions. More recently, several groups have observed that histological IFTA with interstitial inflammation identifies the patients at highest risk for graft loss [2-5]. It is suggested that this latter presentation,

\footnotetext{
* Correspondence: smkurian@scripps.edu

Department of Molecular and Experimental Medicine, The Scripps Research Institute, La Jolla, CA 92037, USA
}

IFTA/inflammation is a workable definition of chronic rejection. It remains uncertain whether all CAN/IFTA with progressive kidney dysfunction is a consequence of immune-mediated chronic rejection or whether there are yet additional mechanisms to discover.

Grading IFTA histology is a means of expressing the severity of chronic kidney injury. Fibrosis represents the end result of kidney tissue injury, which includes the donor organ's history, impact of ischemia/reperfusion, alloimmuneactivated $\mathrm{T}$ and $\mathrm{B}$ cell-mediated, antibody-mediated and inflammation-mediated vascular injury [6-8]. Regardless of the proximate causes, interactions between growth factors and integrin adhesion molecules are important mechanisms in the cycle of injury, repair and fibrosis that are also widely accepted as downstream events in CAN/IFTA [8-13]. 
The goals of the current study were a meta-analysis and the mapping of functional pathways using gene expression array data generated in our own laboratory as well as two independent, external datasets (total 84 kidney transplant biopsies). The general aim of a metaanalysis is to more powerfully estimate the true "effect size" than possible with a single study. There have been other studies that have looked at the gene expression in CAN/IFTA using microarrays. In one study, two independent CAN/IFTA data sets from the public domain (22 and 14 biopsies, respectively) were used to identify 309 genes that were differentially expressed in CAN/ IFTA and were tested as predictors of CAN/IFTA on an additional set of 6 biopsies [14]. By applying Fisher's exact test to identify enriched KEGG pathways, 6 different KEGG pathways, all metabolism related, were overrepresented. A second study of 24 IF/TA biopsies showed that differentially expressed genes were associated with immune response, inflammation, and matrix deposition [15]. Another study looked at gene expression in CAN/ IFTA biopsies describing "pathogenesis-based transcript sets" for injured/diseased tissue [16]. Profiling of 150 kidney transplant biopsies to study the impact of inflammation with fibrosis, showed that Toll-like receptor signaling, antigen presentation/dendritic cell maturation, IFN-gamma-inducible response and cytotoxic $\mathrm{T}$ lymphocyte-associated changes were associated with inflammatory changes [4].

In the current study we focused on identifying the differentially expressed growth factor and integrin signaling pathways since there has not been any previous meta-analysis that has focused on these mechanisms despite literature implicating individual growth factors and integrins with CAN/IFTA. Our study covered biopsies representative of the early development of CAN/ IFTA (Banff grade 1) and the subsequent progression to moderate and severe forms (Banff grades 2 and 3). These new results identify specific growth factor and integrin pathways that allowed us to map a number of potentially novel and drug-able targets.

\section{Results and discussion}

There have been meta-analyses in kidney transplantation, which have been published with specific focuses. The meta-analysis done by Park et al., [17] focused on global profiling using GEO datasets on a broad term called "kidney rejection" that included acute as well as chronic rejection. A similar study that analyzed acute kidney rejection, also used a small number of CAN $(n=7)$ samples and looked at a predefined subset of acute rejection transcripts (ARTS) and pathogenesis based transcripts (PBTs) in these rejection types [18]. Finally another study, again primarily of acute renal allograft rejection, looked at the expression of metzincins (METS), and metzincins and related genes (MARGS) in renal allograft biopsies using four independent microarray data sets [19]. Their data sets also included a small group $(n=7)$ of IFTA samples.

In the current study we specifically wanted to test the hypothesis that a meta-analysis of CAN/IFTA samples from different sources would confirm the role of specific growth factors and/or integrin pathways and potentially reveal new pathways correlative with the progression of CAN/IFTA, which individual studies failed to identify due to the limitations with small sample sizes. We mapped the differentially expressed genes in the varying grades of CAN/IFTA to molecular pathways with a special emphasis on established growth factor and integrin signaling pathways.

\section{Growth factor pathway signaling}

In the first comparison of Banff $0(n=25)$ vs. All CAN/ IFTA (Banff 1, 2\&3; $\mathrm{n}=59$ ), class comparisons yielded 4683 differentially expressed probesets. The differential expression and directionality of fold changes is mentioned for each class comparison in Additional file 1: Tables S1, Additional file 2: Table S2, Additional file 3: Table S3 and Additional file 4: Table S4 for all the results discussed below. Specifically, IPA identified that these 4683 genes fall into 123 significant pathways (SD1). When we applied a Benjamini Hochberg correction for multiple testing to the pathway analysis, there were 74 pathways that were significant $(\mathrm{p}<0.05)$. In this comparison HGF, VEGF, Epidermal Growth Factor (EGF), Insulin-like Growth Factor 1 (IGF-1), TGF-beta and Platelet-derived Growth Factor (PDGF) signaling pathways were all significantly differentially expressed, even with multiple testing correction.

The second comparison was Banff $0(n=25)$ vs. Banff $1(\mathrm{n}=14)$ (mild CAN/IFTA), which yielded 1430 significantly differentially expressed probesets and 84 significant pathways (SD2). HGF, PDGF, VEGF and EGF signaling pathways were differentially expressed as in the comparison to All CAN/IFTA samples. However, Fibroblast Growth Factor (FGF) was also found but the TGF $\beta$ pathway was not significantly expressed.

The third comparison, Banff $0(\mathrm{n}=25)$ vs. Banff $2 \& 3$ $(\mathrm{n}=29)$ (moderate/severe CAN/IFTA), yielded 1978 significantly differentially expressed probesets and 58 significant pathways (SD3). The EGF, FGF, HGF and IGF-1 pathways were all significant. Again, the TGF $\beta$ pathway was not significantly differentially expressed in this analysis. Finally, we compared mild to moderate/severe CAN/IFTA (Banff 1; $\mathrm{n}=25$ vs. Banff $2 \& 3 ; \mathrm{n}=29$ ) and revealed 1362 significantly differentially expressed genes and 44 significant pathways total (SD4). Of 44 pathways identified, there was only one growth factor pathway, IGF-1, with $7 \mathrm{DE}$ genes $(\mathrm{p}=0.05 ; 5 / 7 \mathrm{DE}$ genes were upregulated in moderate/severe CAN/IFTA). However, it is important to note here that the FDR ranges for this 
particular class comparison ranged from 14-19\%, a much less robust gene expression profile statistically than any of the other comparisons performed. Given that everything else was technically the same for all comparisons, we believe these results reflect the biology and demonstrate that the differences between early and more advanced CAN/IFTA as judged by non-quantitative histology in these studies were significantly less. It is possible that as quantitative digital histology becomes more widely available [20] that future comparisons of early to more advanced CAN/IFTA will be more robust.

In sum, the HGF and FGF signaling pathways were significantly upregulated in early CAN/IFTA (Banff 0 vs. 1) and continued to be upregulated in moderate/severe CAN/IFTA (Banff 0 vs. Banff 2\&3). In contrast, it was observed that the VEGF and PDGF signaling pathways were only significantly upregulated in early CAN/IFTA compared to Banff 0 biopsies and IGF1 was the only significant growth factor pathway upregulated in moderate/ severe CAN/IFTA. Table 1 summarizes all the pathways in these four different comparisons.

\section{MAPK dependent growth factor signaling}

Many growth factor pathways are dependent on mitogenactivated protein kinase signaling (MAPK or extracellularsignal-regulated kinase; ERK). We found that LPS-stimulated

\section{Table 1 Growth factor signaling pathways significantly differentially expressed between the Banff grades of CAN/IFTA}

\begin{tabular}{|c|c|}
\hline Normals vs. CAN (Banff $1,2 \& 3$ ) & $\mathrm{p}$-value \\
\hline HGF Signaling & 0.0001 \\
\hline VEGF Signaling* & 0.0016 \\
\hline EGF Signaling $\$$ & 0.0017 \\
\hline IGF-1 Signaling* & 0.0022 \\
\hline TGF- $\beta$ Signaling & 0.0056 \\
\hline PDGF Signaling* & 0.0112 \\
\hline CAN Banff 0 vs. Banff 1 & $\mathrm{p}$-value \\
\hline HGF Signaling $\$$ & 0.0011 \\
\hline FGF Signaling* & 0.0049 \\
\hline PDGF Signaling* & 0.0105 \\
\hline VEGF Signaling* & 0.0158 \\
\hline EGF Signaling $\$$ & 0.0178 \\
\hline CAN Banff 0 vs. Banff $2 \& 3$ & p-value \\
\hline EGF Signaling $\$$ & 0.0145 \\
\hline FGF Signaling* & 0.0257 \\
\hline HGF Signaling & 0.0347 \\
\hline IGF-1 Signaling* & 0.0447 \\
\hline CAN Banff 1 vs. Banff $2 \& 3$ & $\mathrm{p}$-value \\
\hline IGF-1 Signaling* & 0.0447 \\
\hline
\end{tabular}

*Significant in two comparisons.

\$Significant in three or more comparisons.
MAPK, ERK/MAPK and p38 signaling were only significantly differentially expressed in the analysis of Banff 0 vs. Banff 1, 2\&3 CAN/IFTA. It is worth noting that MAPK regulates signaling by TGF $\beta$ [21-23], VEGF [24-26], IGF-1 [27], and HGF [28-30]. These results further support the analysis of the growth factor pathways above suggesting the same pathways are engaged regardless of the histological severity of CAN/IFTA. The expression of the genes in the TGF, IGF-1 and HGF pathways increased in expression from mild to more severe CAN/IFTA, but the opposite trend was seen with VEGF.

\section{Integrin pathway and expression}

Class comparisons of subjects with and without CAN/ IFTA (Banff 0 vs. Banff $1,2 \& 3$ ) showed that six $\beta$ integrin $(1,2,3,5,6,8)$ and six $\alpha$-integrin subunits (v, $\mu$, $1,2,6,9)$ were upregulated. The canonical integrin signaling pathway was also highly differentially expressed in this comparison $\left(\mathrm{p}=4.1 \times 10^{-7}\right)$. Comparisons of specific integrins significantly upregulated in early CAN/ IFTA (Banff 0 vs. Banff 1 ) revealed differential expression of $\beta$ subunits $1,5,6$ and 8 , and $\alpha$ subunits $v, 1,6$ and $\mu$. With progression from mild to moderate/severe CAN/IFTA (Banff 1 vs. Banff 2\&3), the $\alpha 2, \alpha 9, \beta 1$, and $\beta 6$ subunits were upregulated above the levels already present early in CAN/IFTA. The only exception to the upregulation of integrin expression correlating with CAN/ IFTA progression was that integrin $\alpha 6$ was downregulated. All results are summarized in Table 2.

Transcripts for the canonical integrin signaling pathway were also significantly expressed in these latter two comparisons. There are 187 genes in the canonical integrin pathway. Interestingly, only 2 genes, PTEN and PTENP1, were significantly correlated in all three comparisons of CAN/IFTA stages suggesting a potential common signaling mechanism. Thirty-four integrin pathway genes were significantly associated with both Banff 1 and Banff $2 \& 3$ CAN/IFTA and 20 genes were only associated with Banff $2 \& 3$ (Figure 1). In conclusion, many integrin pathway molecules are highly expressed at an early stage of CAN/IFTA and continue to be expressed during the progression to more severe disease, while another set are linked to only more advanced CAN/IFTA (Table 3).

To give some context with regards to the most significant pathways associated with CAN/IFTA progression from the current study we looked at the integrin, IGF and EGF signaling pathways and their regulation with respect to the progression of CAN/IFTA. For the integrin pathway, we observed that in the Banff 0 vs. 1 comparison all differentially expressed genes in the pathway were upregulated in the Banff 1 patients. When we compared this to the expression of the same genes in the Banff 1 vs. Banff 2,3 patients some of the genes like TLN, JNK and CPN were downregulated in the Banff 
Table 2 Integrin subunits differentially expressed between the Banff grades of CAN/IFTA

\begin{tabular}{|c|c|c|c|}
\hline B0 vs. $1+2+3$ & B0 vs. 1 & B0 vs. $2+3$ & B1 vs. $2+3$ \\
\hline$\beta 1(\uparrow 1.40)$ & $\beta 1(\uparrow 1.33)$ & $\beta 1(\uparrow 1.52)$ & $\beta 1(\uparrow 1.42)$ \\
\hline \multicolumn{4}{|l|}{$\beta 2(\uparrow 1.60)$} \\
\hline \multicolumn{4}{|l|}{$\beta 3(\uparrow 1.25)$} \\
\hline$\beta 5(\uparrow 1.23)$ & $\beta 5(\uparrow 1.28)$ & $\beta 5(\uparrow 1.39)$ & \\
\hline$\beta 6(\uparrow 3.07)$ & $\beta 6(\uparrow 2.84)$ & $\beta 6(\uparrow 6.06)$ & $\beta 6(\uparrow 2.14)$ \\
\hline$\beta 8(\uparrow 1.60)$ & $\beta 8(\uparrow 1.85)$ & $\beta 8(\uparrow 1.89)$ & \\
\hline$\alpha 1(\uparrow 1.45)$ & $a 1(\uparrow 1.64)$ & $\alpha 1(\uparrow 1.69)$ & \\
\hline$a 2(\uparrow 1.55)$ & & $a 2(\uparrow 2.05)$ & \\
\hline$a 6(\uparrow 1.55)$ & $a 6(\uparrow 1.67)$ & $a 6(\uparrow 1.87)$ & $a 6(\downarrow 1.38)$ \\
\hline a9( $(1.52)$ & & & $\alpha 9(\uparrow 1.15)$ \\
\hline $\operatorname{av}(\uparrow 1.80)$ & $\operatorname{av}(\uparrow 1.57)$ & $\operatorname{av}(\uparrow 2.02)$ & \\
\hline$\alpha \mu(\uparrow 1.55)$ & $\alpha \mu(\uparrow 1.90)$ & $a \mu(\uparrow 2.53)$ & \\
\hline
\end{tabular}

All p-values are $<0.005$

The direction of change is indicated by the arrow and the numbers in brackets represent the magnitude of change for each integrin subunit. All results shown were statistically significant with $p$ values ranging from $<1 \times 10^{-3}$ to $10^{-7}$.

2,3 patients. Similar changes were seen in both the HGF and the IGF-1 pathways with PKC and JNK (HGF pathway) being downregulated in the Banff 2,3 when compared to Banff 1, and JNK (EGF pathway) was downregulated in Banff 2,3 when compared to Banff 1, respectively. These changes suggest that some of these genes need not be overexpressed and that their downregulation in the Banff 2,3 group when compared to Banff 1 could possibly be a mechanism that promotes CAN/IFTA progression.

\section{Proteogenomic analysis of tissue biopsies}

In order to validate the results of this gene transcription profiling and functional pathway mapping at the protein level, we turned to our previously published analysis of CAN/IFTA biopsies using shotgun tandem mass spectrometry proteomics [31]. Of the 187 integrin pathway molecules, $25(14 \%)$ of them were identified as significantly differentially expressed by proteomics (SD5) (Additional file 5). In this context it is important to note that we had already identified the whole integrin pathway and specifically integrin $\beta 1$ protein as a key player in CAN/ IFTA progression. In addition, proteins of the IGF-1 pathway were also significant in the progression from mild to moderate/severe CAN/IFTA (Banff 1 vs. Banff 2,3; $\mathrm{p}=0.02$ ) and with advanced CAN/IFTA (Banff 0 vs. Banff $2,3 ; \mathrm{p}=0.004)$ at the transcript level, which was similar to what we found at the protein level with the IGF-1 pathway being upregulated in the Banff 2,3 subjects, with tandem mass spectrometry proteomics. Finally, in the development of mild CAN/IFTA (Banff 0 vs. Banff 1), the VEGF and EGF pathways were significant $(\mathrm{p}=0.02$ and 0.05 , respectively) by both transcript and protein.

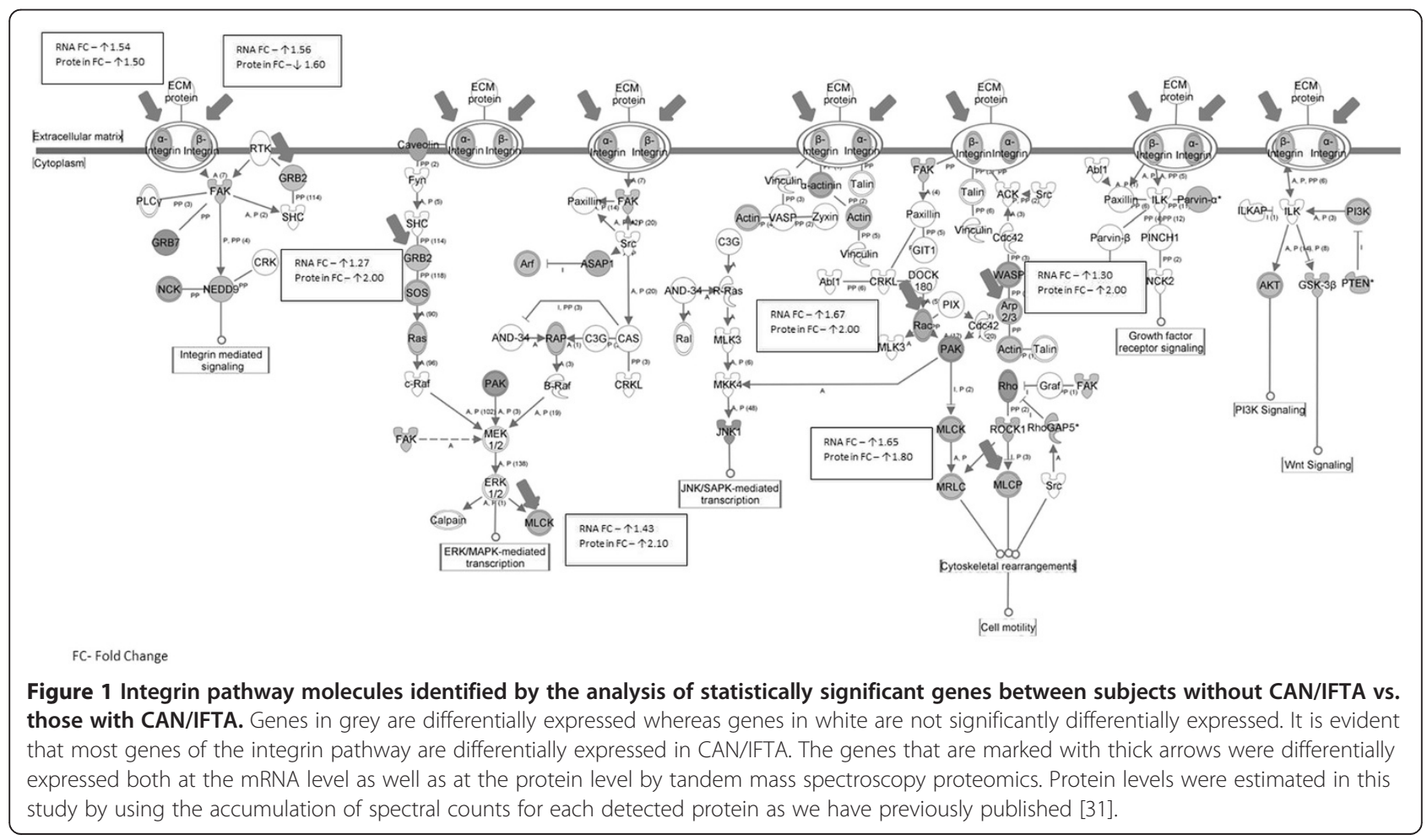


Table 3 An ANOVA analysis of integrin pathway genes significantly differentially expressed between CAN/IFTA Banff 0 (no CAN/IFTA), Banff 1 (mild CAN/IFTA) and Banff 2,3 (moderate severe CAN/IFTA)

\begin{tabular}{|c|c|c|}
\hline Gene symbol & Description & Pairwise significance \\
\hline \multicolumn{3}{|c|}{ Integrin subunits } \\
\hline ITGA1 & integrin, alpha 1 & $(1,2),(1,3)$ \\
\hline ITGA2 & integrin, alpha 2 (CD49B, alpha 2 subunit of VLA-2 receptor) & $(1,3)$ \\
\hline ITGA6 & integrin, alpha 6 & $(1,2),(1,3),(2,3)$ \\
\hline ITGA9 & integrin, alpha 9 & $(1,2),(1,3)$ \\
\hline ITGAD & integrin, alpha D & $(2,1),(3,1)$ \\
\hline ITGAM & integrin, alpha M (complement component 3 receptor 3 subunit) & $(1,2),(1,3)$ \\
\hline ITGAV & integrin, alpha V (vitronectin receptor, alpha polypeptide, antigen CD51) & $(1,2),(1,3)$ \\
\hline ITGB1 & integrin, beta 1 (fibronectin receptor, beta polypeptide, ) & $(1,2),(1,3),(2,3)$ \\
\hline ITGB2 & integrin, beta 2 (complement component 3 receptor 3 and 4 subunit) & $(1,3)$ \\
\hline ITGB3 & integrin, beta 3 (platelet glycoprotein IIla, antigen CD61) & $(1,3)$ \\
\hline ITGB5 & integrin, beta 5 & $(1,2),(1,3)$ \\
\hline ITGB6 & integrin, beta 6 & $(1,2),(1,3),(2,3)$ \\
\hline ITGB8 & integrin, beta 8 & $(1,2),(1,3)$ \\
\hline \multicolumn{3}{|c|}{ Integrin signaling pathway molecules associated with all grades of CAN } \\
\hline PTEN & phosphatase and tensin homolog & $(1,2),(1,3),(2,3)$ \\
\hline PTENP1 & phosphatase and tensin homolog (mutated in multiple advanced cancers 1), pseudogene 1 & $(1,2),(1,3),(2,3)$ \\
\hline \multicolumn{3}{|c|}{ Integrin signaling pathway molecules associated with mild and moderate CAN but cannot distinguish mild from moderate CAN } \\
\hline ACTB & actin, beta & $(1,2),(1,3)$ \\
\hline ACTR2 & ARP2 actin-related protein 2 homolog (yeast) & $(1,2),(1,3)$ \\
\hline ACTR3 & ARP3 actin-related protein 3 homolog (yeast) & $(1,2),(1,3)$ \\
\hline ACTR3B & ARP3 actin-related protein 3 homolog B (yeast) & $(1,2),(1,3)$ \\
\hline ARF4 & ADP-ribosylation factor 4 & $(1,2),(1,3)$ \\
\hline ARF6 & ADP-ribosylation factor 6 & $(1,2),(1,3)$ \\
\hline ARPC1A & actin related protein $2 / 3$ complex, subunit $1 \mathrm{~A}, 41 \mathrm{kDa}$ & $(1,2),(1,3)$ \\
\hline ARPC2 & actin related protein 2/3 complex, subunit 2, $34 \mathrm{kDa}$ & $(1,2),(1,3)$ \\
\hline ARPC4 & actin related protein $2 / 3$ complex, subunit 4, $20 \mathrm{kDa}$ & $(2,1),(3,1)$ \\
\hline ARPC5 & actin related protein 2/3 complex, subunit 5, $16 \mathrm{kDa}$ & $(1,2),(1,3)$ \\
\hline CAPN10 & calpain 10 & $(2,1),(3,1)$ \\
\hline CAPN6 & calpain 6 & $(2,1),(3,1)$ \\
\hline CRKL & v-crk sarcoma virus CT10 oncogene homolog (avian)-like & $(1,2),(1,3)$ \\
\hline GRB2 & growth factor receptor-bound protein 2 & $(1,2),(1,3)$ \\
\hline KRAS & v-Ki-ras2 Kirsten rat sarcoma viral oncogene homolog & $(1,2),(1,3)$ \\
\hline MYLK & myosin, light chain kinase & $(1,2),(1,3)$ \\
\hline NRAS & neuroblastoma RAS viral (v-ras) oncogene homolog & $(1,2),(1,3)$ \\
\hline PAK2 & p21 (CDKN1A)-activated kinase 2 & $(1,2),(1,3)$ \\
\hline PAK7 & p21(CDKN1A)-activated kinase 7 & $(2,1),(3,1)$ \\
\hline PIK3C2A & phosphoinositide-3-kinase, class 2, alpha polypeptide & $(1,2),(1,3)$ \\
\hline PIK3C3 & phosphoinositide-3-kinase, class 3 & $(1,2),(1,3)$ \\
\hline PIK3CA & phosphoinositide-3-kinase, catalytic, alpha polypeptide & $(1,2),(1,3)$ \\
\hline PIK3CB & phosphoinositide-3-kinase, catalytic, beta polypeptide & $(1,2),(1,3)$ \\
\hline PIK3R3 & phosphoinositide-3-kinase, regulatory subunit 3 ( $p 55$, gamma) & $(1,2),(1,3)$ \\
\hline PPP1CB & protein phosphatase 1, catalytic subunit, beta isoform & $(1,2),(1,3)$ \\
\hline PPP1CC & protein phosphatase 1, catalytic subunit, gamma isoform & $(1,2),(1,3)$ \\
\hline PPP1R12A & protein phosphatase 1, regulatory (inhibitor) subunit 12A & $(1,2),(1,3)$ \\
\hline ROCK1 & Rho-associated, coiled-coil containing protein kinase 1 & $(1,2),(1,3)$ \\
\hline
\end{tabular}


Table 3 An ANOVA analysis of integrin pathway genes significantly differentially expressed between CAN/IFTA Banff 0 (no CAN/IFTA), Banff 1 (mild CAN/IFTA) and Banff 2,3 (moderate severe CAN/IFTA) (Continued)

\begin{tabular}{|c|c|c|}
\hline RRAS2 & related RAS viral (r-ras) oncogene homolog 2 & $(1,2),(1,3)$ \\
\hline SOS2 & son of sevenless homolog 2 (Drosophila) & $(2,1),(3,1)$ \\
\hline TLN1 & talin 1 & $(2,1),(3,1)$ \\
\hline TSPAN3 & tetraspanin 3 & $(2,1),(3,1)$ \\
\hline TTN & titin & $(2,1),(3,1)$ \\
\hline WIPF1 & WAS/WASL interacting protein family, member 1 & $(1,2),(1,3)$ \\
\hline \multicolumn{3}{|c|}{ Integrin signaling pathway molecules specifically associated with moderate CAN } \\
\hline ARF1 & ADP-ribosylation factor 1 & $(1,3)$ \\
\hline ARPC1B & actin related protein $2 / 3$ complex, subunit $1 \mathrm{~B}, 41 \mathrm{kDa}$ & $(1,3)$ \\
\hline ARPC5L & actin related protein $2 / 3$ complex, subunit 5-like & $(1,3)$ \\
\hline CAPN7 & calpain 7 & $(1,3)$ \\
\hline GIT1 & G protein-coupled receptor kinase interactor 1 & $(3,1)$ \\
\hline ILK & integrin-linked kinase & $(3,1)$ \\
\hline ITGB3BP & integrin beta 3 binding protein (beta3-endonexin) & $(1,3)$ \\
\hline MLCK & MLCK protein & $(3,1)$ \\
\hline NCK2 & NCK adaptor protein 2 & $(1,3)$ \\
\hline PAK3 & p21 (CDKN1A)-activated kinase 3 & $(1,3)$ \\
\hline PIK3C2B & phosphoinositide-3-kinase, class 2, beta polypeptide & $(1,3)$ \\
\hline PIK3CD & phosphoinositide-3-kinase, catalytic, delta polypeptide & $(1,3)$ \\
\hline PIK3CG & phosphoinositide-3-kinase, catalytic, gamma polypeptide & $(3,1)$ \\
\hline PIK3R1 & phosphoinositide-3-kinase, regulatory subunit 1 (p85 alpha) & $(1,3)$ \\
\hline PPP1CA & protein phosphatase 1, catalytic subunit, alpha isoform & $(1,3)$ \\
\hline PPP1R12B & protein phosphatase 1 , regulatory (inhibitor) subunit $12 \mathrm{~B}$ & $(3,1)$ \\
\hline SOS1 & son of sevenless homolog 1 (Drosophila) & $(3,1)$ \\
\hline TSPAN4 & tetraspanin 4 & $(1,3)$ \\
\hline TSPAN5 & tetraspanin 5 & $(1,3)$ \\
\hline WASL & Wiskott-Aldrich syndrome-like & $(3,1)$ \\
\hline
\end{tabular}

Numbers in brackets represent the pair-wise comparison significance $(p<0.005)$ where $1=$ Banff $0,2=$ Banff 1 and $3=$ Banff 2,3 .

\section{Drug target and biomarker analysis}

We used a new module in IPA based on literature and public drug target databases to determine how many of the molecules we identified by gene expression profiling in CAN/IFTA are targeted by known drugs (SD6) (Additional file 6). Of the 4109 differentially expressed genes between Banff 0 vs. All CAN/IFTA, 129 genes are targets of known drugs. In the differentially expressed growth factor pathways (HGF, VEGF, EGF, IGF-1, TGF- $\beta$ and PDGF), 10 of the 78 molecules we identified are targets of known drugs. In the integrin pathway, there are only 2 genes known to be targets of drugs (ITGB5 and ITGAV) and both are differentially expressed in our data. We also used Ingenuity to identify genes that are known or potential biomarkers defined in the literature (SD7) Additional file (7). For example, of the 78 molecules associated with growth factor signaling, 34 (44\%) of the genes are biomarker candidates and 368 of the total 4109 differentially expressed genes have been described as potential biomarkers in the literature in various models of disease.
The advantages of combining information from multiple existing microarray studies in a meta-analysis are a larger sample size, minimization of center-specific effects, and the application of a single data analysis pipeline. Metaanalyses also represent savings in time and costs by making comprehensive use of already available data. The present study represents a mechanism-focused, bioinformaticsdriven meta-analysis of gene expression in kidney transplant biopsies with CAN/IFTA. We demonstrate that the differential activation and expression of specific growth factors, integrins and signaling pathways distinguishes the different stages of CAN/IFTA and correlate with progression of disease.

In our data, VEGF and PDGF signaling pathways were significantly upregulated in early CAN/IFTA but were not upregulated in biopsies with moderate/severe CAN/ IFTA. This is consistent with an increased expression of VEGF in interstitial cells and arteries developing intimal and adventitial fibrosis in kidneys undergoing vascular rejection [32]. In contrast, only differential expression of 
IGF-1 signaling correlated with the progression from mild (Banff 1) to moderate/severe CAN/IFTA (Banff 2\&3). Perhaps purposeful inhibition of IGF-1 signaling might be a candidate for therapy once CAN/IFTA is already present. However, these results also suggest that most of the growth factor pathways driving CAN/IFTA are present early in the course and not changing significantly as it progresses. It is worth commenting that these results also suggest caution that once patients present with early CAN/IFTA (e.g. protocol biopsy), there is a high likelihood that it will eventually progress.

Interestingly, TGF $\beta$ was only differentially expressed when comparing healthy transplants (Banff 0 ) to those with any grade of CAN/IFTA. However, TGF $\beta$ expression does not distinguish between mild and moderate/severe disease. Evidence for the early activation of TGF $\beta$ has been shown in a number of studies as early as 2-6 months and is often reviewed as a critical growth factor for interstitial fibrosis [33,34]. A pediatric study showed that relatively early TGF $\beta$ expression in grafts 100 days after transplantation correlates with decreased long-term graft function and increased graft fibrosis at 3 years [35]. siRNAs directed against the TGF $\beta$ receptor improved renal fibrosis in a mouse model of interstitial nephritis [36]. Our analysis is consistent with these studies in identifying differential TGF $\beta$ pathway expression in biopsies with CAN/IFTA compared to healthy transplant biopsies. However, the fact that there is no further increase in TGF $\beta$ gene expression despite increasing severity of disease suggests that other pathways mediate progressive fibrosis and tubular atrophy.

The HGF and FGF signaling pathways were significantly upregulated in early CAN/IFTA, but unlike TGF $\beta$ were further upregulated in biopsies of moderate/severe CAN/IFTA. HGF, a member of the FGF family, is known to mediate the repair and maintenance of the kidney epithelium. HGF is nephron-protective [37] and suppresses interstitial fibrosis in a rat model of obstructive nephropathy [38]. Exogenous administration of HGF has been shown in a rat model of CAN to prevent the progression of IFTA [39]. Thus, one possibility for our results in these human patients is that up-regulation of the intrinsic HGF pathway acts as a compensatory mechanism protecting the progression of chronic injury and fibrosis. It adds caution to the tendency of advocating blockade of any pathway found in any pathological condition.

FGF is known to stimulate endothelial cell proliferation, degrade ECM and interact with VEGF [40]. In situ hybridization and immunohistochemical analysis showed that mRNA for FGF-1 and its high-affinity receptors were increased in the tubular epithelium, inflammatory cell infiltrates, and neovascular structures of kidney transplant patients who underwent nephrectomy after graft loss for what the authors called chronic rejection
[41]. Our results are consistent with this role for FGF-1 in biopsy-proven CAN/IFTA.

As already noted, VEGF and PDGF signaling pathways were significantly upregulated with mild CAN/IFTA, but not further upregulated with moderate/severe CAN/ IFTA. In a different set of transplant biopsies done several years ago, we also demonstrated the up-regulation of PDGF with CAN/IFTA [42]. Thus, it may be that VEGF and PDGF signaling is important early in the establishment of chronic allograft injury, perhaps by amplifying the injury driven by FGF-1.

The MAPK-dependent growth factor signaling pathways, ERK and p38, were significantly differentially expressed in our study between well functioning transplants vs. any grade of CAN/IFTA. In rat models, the inhibition of p38 MAPK by treatment with a specific p38 MAPK inhibitor resulted in reduced CAN/IFTA with preserved renal function and survival $[43,44]$.

We also show that specific integrins are upregulated in the progression of CAN/IFTA (Table 2) and these results correlate with the parallel up-regulation of the canonical integrin signaling pathway (Figure 1). The integrin subunits $\beta 1, \beta 6$ and $\alpha 6$ were consistently and significantly differentially expressed in all comparisons. An earlier study in rats demonstrated that blockade of interactions between $\alpha 4 \beta 1$ integrin and fibronectin prevents the development of chronic rejection in cardiac allografts [45]. However, we note that our kidney results do not demonstrate differential expression of the $\alpha 4$ chain. One explanation is that the $\beta 1$ subunit regulates the assembly of the $\alpha 4 \beta 1$ integrin in kidneys. A study of integrin expression in allograft rejection showed that $\alpha v \beta 6$ was involved in the re-epithelialization of healing isografts in an animal model of chronic progressive lung allograft rejection [46]. In two other studies, mice with bleomycin-induced pulmonary fibrosis were treated with an anti- $\alpha \mathrm{v} \beta 6$ monoclonal antibody $[47,48]$. Treated animals showed reduced fibrosis and these results were confirmed using transgenic and knock-out animals. In a published meta-analysis of human kidney transplant biopsies, 309 genes were identified as associated with CAN/IFTA [14]. We identified 47 genes from this set in the present analysis including the $\alpha 6$ chain. Thus, these many lines of evidence converge to identify roles for several specific growth factors and integrin adhesion pathways in chronic kidney transplant injury.

Our analysis of the correlation of the genomic findings with our previously published proteomic work clearly identified the integrin pathway (Figure 1) and the IGF-1 pathway as being differentially regulated and as pathways that specifically affect CAN/IFTA progression. This is very relevant because both these pathways are validated both at the mRNA as well as the protein level and could potentially be the highest priority pathways to address 
with animal models to study specific mechanisms of CAN/IFTA.

Finally, we used a new module in Ingenuity Pathway Analysis to search for drug targets in our differentially expressed genes and pathways (SD6). For example, in the context of the integrins, there are three drugs that target the integrin $\alpha v$ subunit, two antibodies and one cyclic RGD pentapeptide and the pentapeptide also targets another differentially expressed integrin subunit, $\beta 5$ [49]. Ten of 78 molecules involved in known growth factor signaling pathways (HGF, VEGF, EGF, IGF-1, TGF- $\beta$, PDGF) were targets of over 30 different drugs. Many of these drugs are already FDA-approved while others are in various phases of clinical trials for cancer, hypertension and diabetes, including specific kinase inhibitors, receptor signaling blockers and monoclonal antibodies. The potential of using bioinformatic tools to integrate public data with clinical gene profiling results and identify drug targets or candidate biomarkers is still largely untested. However, two recent studies from Stanford used a similar approach to identify drug targets for cancer, one of which they validated, or search for transplant biomarkers [50,51].

We would also like to draw the attention of the readers to some of the limitations of our study. First, even though we used 84 samples to perform a metaanalysis and despite the fact that we were adequately powered to detect gene expression changes greater than two-fold, the findings of the current study need to be validated in a larger cohort of samples, especially of the different subtypes of CAN before it can be generalized. Similarly, we cannot discount the effect of different immunosuppressive drug regimens and levels on the gene expression, though all the studied patients were on a primary calcineurin inhibitor protocol. The correlations between transcript levels and protein levels have been shown to be relatively poor in earlier studies[52,53]; however several recent studies have shown that these correlations are a lot better than previously shown due to the technical advancements in protein detection by the latest mass spectrometry technologies[54,55]. Our current study used tandem mass spectrometry proteomics data from an earlier study of ours using liquid chromatography coupled with an ion trap instrument (MudPIT protocol for LC/ MS/MS) [31]. Newer technologies have significantly enhanced mass detection accuracies and targeted proteomics using alternative mass spectrometry technologies such as multiple single reaction monitoring (MSRM) and triple quadropole TOF instruments will now allow investigators to more accurately identify and even quantify protein level changes for better correlations with gene expression levels profiled in the same samples. The importance of the present work is to establish a clear set of candidate genes and functional pathways that would merit the next stage of experimental efforts to validate these with proteomics.

Table 4 Clinical characteristics for the 33 samples that were analyzed with microarrays in our laboratory

\begin{tabular}{|c|c|c|c|}
\hline & Banffo & CAN & Significance ${ }^{*}$ \\
\hline Subject Numbers & 9 & 24 & \\
\hline Recipient Age $\pm \mathrm{SD}^{\ddagger}$ & $49.7 \pm 12.9$ & $45.7 \pm 13.1$ & $N S^{\wedge}$ \\
\hline \% Female Recipients & 66.7 & 45.8 & NS \\
\hline \% Recipient African American & 0 & 8.33 & NS \\
\hline \% Pre-tx Type II Diabetes & 25 & 17.4 & NS \\
\hline$\%$ PRA > 20 & 0 & 9.5 & NS \\
\hline HLA Mismatch \pm SD & $2.3 \pm 1.3$ & $2.6 \pm 3.2$ & NS \\
\hline \% Deceased Donor & 66.7 & 69.6 & NS \\
\hline Donor Age \pm SD & $31.4 \pm 13.6$ & $41.6 \pm 14.7$ & NS \\
\hline$\%$ Female Donors & 33.3 & 41.6 & NS \\
\hline$\%$ Donor African American & 0 & 6.7 & NS \\
\hline$\%$ Induction & 66.7 & 87.5 & NS \\
\hline Serum Creatinine \pm SD & $3.07 \pm 1.2$ & $1.78 \pm 1.1$ & 0.01 \\
\hline Time to Biopsy (Days) \pm SD & $691 \pm 550$ & $2009 \pm 1367$ & 0.0004 \\
\hline$\%$ Calcineurin Inhibitors & 87.5 & 75 & NS \\
\hline \% Mycophenolic Acid Derivatives & 55.6 & 70.8 & NS \\
\hline$\%$ Oral Steroids & 44.5 & 100 & 0.0005 \\
\hline C4d Positive Staining (\%) & 0 & 13 & NS \\
\hline
\end{tabular}

* Significance for all comparisons were determined with paired Students t-test for pair-wise comparisons of data with Standard Deviations and for dichotomous

data comparisons by Chi-Square.

₹ $\mathrm{SD}=$ standard deviation from the mean.

$\wedge \mathrm{NS}=$ not significant $(p \geq 0.05)$. 


\section{Conclusions}

Putting the clinical potential of these drug candidate and biomarker correlations into perspective, there are multiple lines of published scientific data that the growth factor signaling pathways we describe here are highly likely to be linked mechanistically to the development and/or progression of CAN/IFTA. Clearly, we cannot determine a root cause of CAN/IFTA simply by gene profiling of biopsies. However, we are describing evidence for multiple and powerful tissue injury and remodeling pathways linked to growth factors and integrin adhesion molecules. The initiation and progression of chronic allograft injury could be driven by immunemediated rejection through multiple mechanisms and impacted upon by drug toxicities and concomitant medical problems. Regardless, the possibility raised here is that the integrins and growth factors identified in this study are attractive candidates for developing animal models to study the effects of their inhibition/activation. Such work could be the starting point for translational studies into how these molecules modulate signaling in patients with early CAN/IFTA could be a successful way of mitigating the damage caused by whatever the underlying primary mechanism may be and the large number of known drug candidates available is encouraging.

\section{Methods}

\section{Microarray analysis of tissue biopsies}

DNA Microarray CEL files from 84 kidney transplant biopsy samples were studied. We processed 33 samples (24 CAN and 9 Banffo), and the others were from two independent studies (GSE7392 (16 CAN and 14 Banffo) [17] and GSE9493 (16 CAN) [18,19]) from the NIH NCBI GEO repository. The clinical characteristics of the 33 samples processed by us are given in Table 4. All samples were obtained as part of the Transplant Genomics Collaborative Group (TGCG) and approved by the review boards of the participating transplant centers (Scripps Green Hospital, Cleveland Clinic Foundation, Mendez National Institute for Transplantation, Mayo Clinic Arizona and U Colorado Health Sciences). All samples were hybridized on Affymetrix HG-U133 Plus 2.0 Arrays to avoid cross-platform comparisons. We used ComBat, a software that uses Bayes frameworks for adjusting data for batch effects that is robust to outliers in small sample sizes and performs comparable to existing methods for large samples [56]. BRB Array Tools (version 3.8.1) was used to perform class comparisons between classes ( $p$ value $<0.005$ defined as significant after multiple testing adjustments. The resulting FDR ranges reported for all but one comparison were from $1 \times 10^{-7}$ to $6 \%$. The only exception to this FDR range was the comparison done between early CAN (Banff1) vs. moderate to severe CAN (Banff2,3) where the FDRs ranged from 14 to 19\%, consistent with the conclusion that the identified gene changes were much less robust for this comparison. Details on the microarray data processing have been previously described [57]. Pathway, network and drug target analysis was performed using Ingenuity Pathway Analysis (IPA). Pathway significance was determined using a righttailed Fisher's Exact Test, where only over-represented functions or pathways are considered significant at a $\mathrm{p}$ value $\leq 0.05$.

\section{Proteogenomic analysis of tissue biopsies}

All proteomic data comparisons were made using our previously published study that revealed about 1400 proteins with unique expression profiles tracing the progression from normal transplant biopsies to increasingly severe grades of CAN/IFTA [31].

\section{Consent}

Written informed consent was obtained from all the patients in this study for publication of this manuscript.

\section{Additional files}

\section{Additional file 1: Banff 0 vs. All CAN. \\ Additional file 2: CAN Banff 0 vs Banff 1. \\ Additional file 3: CAN Banff 0 vs. Banff 2,3. \\ Additional file 4: CAN Banff 1 vs Banff 2,3. \\ Additional file 5: 25 integrin pathway molecules identified as significantly differentially expressed by proteomics. \\ Additional file 6: Drug Targets - Healthy transplants vs. CAN/IFTA subjects (129/4109 molecules).}

Additional file 7: Growth Factor Signaling Pathway biomarker Candidates (34/78 molecules).

\section{Competing interests}

The author(s) declare that they have no competing interests.

\section{Authors' contributions}

AD: Participated in research design, participated in the writing of the paper and participated in data analysis. ER: Participated in the performance of the research. TM: Participated in the performance of the research. $\mathrm{SRH}$ :

Participated in research design and participated in the performance of the research. DRS: Participated in research design and participated in the writing of the paper. SMK: Participated in research design, participated in the writing of the paper and participated in data analysis. All authors read and approved the final manuscript.

\section{Acknowledgments}

Funding was provided by NIH grant U19 Al52349 (DRS/SMK), the Molly Baber Research Fund, and the Verna Harrah Research Fund. The patient biopsy samples from our laboratory were obtained from the Transplant Genomics Collaborative Group (TGCG) whose investigators (PI) and research coordinators $(\mathrm{RC})$ made this possible. The following are the clinical centers, PIs and research co-coordinators: 1) Scripps Green Hospital, PI: Chris Marsh, RC: Joanna Sung, Andrew Johnson; 2) Cleveland Clinic Foundation, PI: Stuart Flechner, RC: Barbara Mastroianni, Kathy Savas; 3) Mendez National Institute for Transplantation, PI: lan Hutchinson, RC: Caron Hutchinson, Jose Escobar; 4) Mayo Clinic - Phoenix, PI: Raymond Heilman, RC: Michael Leonard; 5) U Colorado Health Sciences Center, PI: Lawrence Chan, RC: Janis Cicerchi, Lois Clegg; 6) Texas Institute of Medicine and Surgery, PI: Steven Rosenblatt, RC: 
Jodell McCracken; 7) University of Michigan, Pl: Randall Sung, RC: Peggy Walz, Mary Maliarik.

Received: 18 October 2012 Accepted: 18 April 2013

Published: 23 April 2013

\section{References}

1. Solez K, Colvin RB, Racusen LC, Sis B, Halloran PF, Birk PE, Campbell PM, Cascalho M, Collins AB, Demetris AJ, et al: Banff '05 Meeting Report: differential diagnosis of chronic allograft injury and elimination of chronic allograft nephropathy ('CAN'). American journal of transplantation: official journal of the American Society of Transplantation and the American Society of Transplant Surgeons 2007, 7(3):518-526.

2. Mannon RB, Matas AJ, Grande J, Leduc R, Connett J, Kasiske B, Cecka JM, Gaston RS, Cosio F, Gourishankar S, et al: Inflammation in areas of tubular atrophy in kidney allograft biopsies: a potent predictor of allograft failure. Am J Transplant, 10(9):2066-2073.

3. Mengel M, Reeve J, Bunnag S, Einecke G, Jhangri GS, Sis B, Famulski K, Guembes-Hidalgo L, Halloran PF: Scoring total inflammation is superior to the current Banff inflammation score in predicting outcome and the degree of molecular disturbance in renal allografts. American journal of transplantation : official journal of the American Society of Transplantation and the American Society of Transplant Surgeons 2009, 9(8):1859-1867.

4. Park WD, Griffin MD, Cornell LD, Cosio FG, Stegall MD: Fibrosis with inflammation at one year predicts transplant functional decline. Journal of the American Society of Nephrology: JASN 2010, 21(11):1987-1997.

5. Sis B, Jhangri GS, Bunnag S, Allanach K, Kaplan B, Halloran PF: Endothelial gene expression in kidney transplants with alloantibody indicates antibody-mediated damage despite lack of $\mathrm{C} 4 \mathrm{~d}$ staining. American journal of transplantation: official journal of the American Society of Transplantation and the American Society of Transplant Surgeons 2009, 9(10):2312-2323.

6. Jevnikar AM, Mannon RB: Late kidney allograft loss: what we know about it, and what we can do about it. Clin J Am Soc Nephrol 2008, 3(Suppl 2):S56-67.

7. Robertson H, Ali S, McDonnell BJ, Burt AD, Kirby JA: Chronic renal allograft dysfunction: the role of $T$ cell-mediated tubular epithelial to mesenchymal cell transition. Journal of the American Society of Nephrology: JASN 2004, 15(2):390-397.

8. Strutz F: Pathogenesis of tubulointerstitial fibrosis in chronic allograft dysfunction. Clin Transplant 2009, 23(Suppl 21):26-32.

9. Chapman JR, O'Connell PJ, Nankivell BJ: Chronic renal allograft dysfunction. Journal of the American Society of Nephrology: JASN 2005, 16(10):3015-3026.

10. Nankivell BJ, Chapman JR: Chronic allograft nephropathy: current concepts and future directions. Transplantation 2006, 81(5):643-654.

11. Sampson NS, Ryan ST, Enke DA, Cosgrove D, Koteliansky V, Gotwals P: Global gene expression analysis reveals a role for the alpha 1 integrin in renal pathogenesis. J Biol Chem 2001, 276(36):34182-34188.

12. Sharma K, Ziyadeh FN: The emerging role of transforming growth factorbeta in kidney diseases. Am J Physiol 1994, 266(6 Pt 2):F829-842.

13. Yates PJ, Nicholson ML: The aetiology and pathogenesis of chronic allograft nephropathy. Transpl Immunol 2006, 16(3-4):148-157.

14. Kong X, Mas V, Archer KJ: A non-parametric meta-analysis approach for combining independent microarray datasets: application using two microarray datasets pertaining to chronic allograft nephropathy. BMC Genomics 2008, 9:98.

15. Maluf DG, Mas VR, Archer KJ, Yanek K, Gibney EM, King AL, Cotterell A, Fisher RA, Posner MP: Molecular pathways involved in loss of kidney graft function with tubular atrophy and interstitial fibrosis. Mol Med 2008, 14(5-6):276-285

16. Halloran PF, de Freitas DG, Einecke G, Famulski KS, Hidalgo LG, Mengel M, Reeve J, Sellares J, Sis B: The molecular phenotype of kidney transplants. American journal of transplantation: official journal of the American Society of Transplantation and the American Society of Transplant Surgeons 2010, 10(10):2215-2222.

17. Park WD, Stegall MD: A meta-analysis of kidney microarray datasets: investigation of cytokine gene detection and correlation with rt-PCR and detection thresholds. BMC Genomics 2007, 8:88.

18. Saint-Mezard P, Berthier CC, Zhang H, Hertig A, Kaiser S, Schumacher M, Wieczorek G, Bigaud M, Kehren J, Rondeau E, et al: Analysis of independent microarray datasets of renal biopsies identifies a robust transcript signature of acute allograft rejection. Transplant international: official journal of the European Society for Organ Transplantation 2009, 22(3):293-302.

19. Rodder S, Scherer A, Raulf F, Berthier CC, Hertig A, Couzi L, Durrbach A, Rondeau E, Marti HP: Renal allografts with IF/TA display distinct expression profiles of metzincins and related genes. American journal of transplantation: official journal of the American Society of Transplantation and the American Society of Transplant Surgeons 2009, 9(3):517-526.

20. Isse K, Lesniak A, Grama K, Roysam B, Minervini MI, Demetris AJ: Digital transplantation pathology: combining whole slide imaging, multiplex staining and automated image analysis. American journal of transplantation: official journal of the American Society of Transplantation and the American Society of Transplant Surgeons 2012, 12(1):27-37.

21. Cordenonsi M, Montagner M, Adorno M, Zacchigna L, Martello G, Mamidi A, Soligo S, Dupont S, Piccolo S: Integration of TGF-beta and Ras/MAPK signaling through p53 phosphorylation. Science 2007, 315(5813):840-843

22. Galliher AJ, Schiemann WP: Src phosphorylates Tyr284 in TGF-beta type II receptor and regulates TGF-beta stimulation of p38 MAPK during breast cancer cell proliferation and invasion. Cancer Res 2007, 67(8):3752-3758.

23. Kim ES, Kim MS, Moon A: TGF-beta-induced upregulation of MMP-2 and MMP-9 depends on p38 MAPK, but not ERK signaling in MCF10A human breast epithelial cells. Int J Oncol 2004, 25(5):1375-1382.

24. Botero TM, Son JS, Vodopyanov D, Hasegawa M, Shelburne CE, Nor JE: MAPK signaling is required for LPS-induced VEGF in pulp stem cells. J Dent Res, 89(3):264-269.

25. Doanes AM, Hegland DD, Sethi R, Kovesdi I, Bruder JT, Finkel T: VEGF stimulates MAPK through a pathway that is unique for receptor tyrosine kinases. Biochem Biophys Res Commun 1999, 255(2):545-548.

26. Takahashi M, Matsui A, Inao M, Mochida S, Fujiwara K: ERK/MAPK-dependent $\mathrm{PI} 3 \mathrm{~K} / \mathrm{Akt}$ phosphorylation through VEGFR-1 after VEGF stimulation in activated hepatic stellate cells. Hepatol Res 2003, 26(3):232-236.

27. Choi YS, Cho HY, Hoyt KR, Naegele JR, Obrietan K: IGF-1 receptor-mediated ERK/MAPK signaling couples status epilepticus to progenitor cell proliferation in the subgranular layer of the dentate gyrus. GLIA 2008, 56(7):791-800.

28. Awasthi $V$, King RJ: PKC, p42/p44 MAPK, and p38 MAPK are required for HGF-induced proliferation of H441 cells. Am J Physiol Lung Cell Mol Physiol 2000, 279(5):L942-949.

29. Liu ZX, Nickel CH, Cantley LG: HGF promotes adhesion of ATP-depleted renal tubular epithelial cells in a MAPK-dependent manner. Am J Physiol Renal Physiol 2001, 281(1):F62-70.

30. Wang M, Crisostomo PR, Herring C, Meldrum KK, Meldrum DR: Human progenitor cells from bone marrow or adipose tissue produce VEGF, HGF, and IGF-I in response to TNF by a p38 MAPK-dependent mechanism. Am J Physiol Regul Integr Comp Physiol 2006, 291(4):R880-884.

31. Nakorchevsky A, Hewel JA, Kurian SM, Mondala TS, Campbell D, Head SR, Marsh CL, Yates JR 3rd, Salomon DR: Molecular mechanisms of chronic kidney transplant rejection via large-scale proteogenomic analysis of tissue biopsies. J Am Soc Nephrol, 21(2):362-373.

32. Grone HJ, Simon M, Grone EF: Expression of vascular endothelial growth factor in renal vascular disease and renal allografts. J Pathol 1995, 177(3):259-267.

33. Del Prete D, Ceol M, Anglani F, Vianello D, Tiralongo E, Valente M, Graziotto R, Bonfante L, Scaparrotta G, Furian L, et al: Early activation of fibrogenesis in transplanted kidneys: a study on serial renal biopsies. Exp Mol Pathol 2009, 87(2):141-145.

34. Baboolal K, Jones GA, Janezic A, Griffiths DR, Jurewicz WA: Molecular and structural consequences of early renal allograft injury. Kidney Int 2002, 61(2):686-696

35. Ishimura T, Ishida T, Fujisawa M: Significance of early biopsy in pediatric kidney transplantation. Aktuelle Urol 2003, 34(4):234-238.

36. Kushibiki T, Nagata-Nakajima N, Sugai M, Shimizu A, Tabata Y: Delivery of plasmid DNA expressing small interference RNA for TGF-beta type II receptor by cationized gelatin to prevent interstitial renal fibrosis. J Control Release 2005, 105(3):318-331.

37. Vargas GA, Hoeflich A, Jehle PM: Hepatocyte growth factor in renal failure: promise and reality. Kidney Int 2000, 57(4):1426-1436.

38. Mizuno S, Matsumoto K, Nakamura T: Hepatocyte growth factor suppresses interstitial fibrosis in a mouse model of obstructive nephropathy. Kidney Int 2001, 59(4):1304-1314. 
39. Azuma H, Takahara S, Matsumoto K, Ichimaru N, Wang JD, Moriyama T, Waaga AM, Kitamura M, Otsuki Y, Okuyama A, et al: Hepatocyte growth factor prevents the development of chronic allograft nephropathy in rats. Journal of the American Society of Nephrology: JASN 2001, 12(6):1280-1292.

40. Thompson A, Bhandari V: Pulmonary Biomarkers of Bronchopulmonary Dysplasia. Biomark Insights 2008, 3:361-373.

41. Kerby JD, Luo KL, Ding Q, Tagouri Y, Herrera GA, Diethelm AG, Thompson $J A$ : Immunolocalization of acidic fibroblast growth factor and receptors in the tubulointerstitial compartment of chronically rejected human renal allografts. Transplantation 1997, 63(7):988-995.

42. Flechner SM, Kurian SM, Solez K, Cook DJ, Burke JT, Rollin H, Hammond JA, Whisenant T, Lanigan CM, Head SR, et al: De novo kidney transplantation without use of calcineurin inhibitors preserves renal structure and function at two years. American journal of transplantation: official journal of the American Society of Transplantation and the American Society of Transplant Surgeons 2004, 4(11):1776-1785.

43. Tan HB, Feng Y, Liu M, Wu YC: Protective effects of FR167653 on chronic allograft nephropathy by inhibiting p38 MAPK in rats. Transplant Proc 2008, 40(5):1685-1689.

44. Wada T, Azuma H, Furuichi K, Sakai N, Kitagawa K, Iwata Y, Matsushima K, Takahara S, Yokoyama H, Kaneko S: Reduction in chronic allograft nephropathy by inhibition of p38 mitogen-activated protein kinase. Am J Nephrol 2006, 26(4):319-325.

45. Coito AJ, Korom S, Hancock WW, Kupiec-Weglinski JW: Blockade of alpha 4 beta 1-integrin-fibronectin adhesive interactions prevents chronic allograft rejection in sensitized recipients. Transplant Proc 1998, 30(4):939-940

46. Dosanjh A, Ikonen T, Morris R: Respiratory epithelial expression of integrin alphaVbeta6 in chronic progressive allograft rejection. J Heart Lung Transplant 2004, 23(4):456-460.

47. Horan GS, Wood S, Ona V, Li DJ, Lukashev ME, Weinreb PH, Simon KJ, Hahm K, Allaire NE, Rinaldi NJ, et al: Partial inhibition of integrin alpha(v)beta6 prevents pulmonary fibrosis without exacerbating inflammation. Am J Respir Crit Care Med 2008, 177(1):56-65.

48. Puthawala K, Hadjiangelis N, Jacoby SC, Bayongan E, Zhao Z, Yang Z, Devitt ML, Horan GS, Weinreb PH, Lukashev ME, et al: Inhibition of integrin alpha (v)beta6, an activator of latent transforming growth factor-beta, prevents radiation-induced lung fibrosis. Am J Respir Crit Care Med 2008, 177(1):82-90.

49. Eskens FA, Dumez H, Hoekstra R, Perschl A, Brindley C, Bottcher S, Wynendaele W, Drevs J, Verweij J, van Oosterom AT: Phase I and pharmacokinetic study of continuous twice weekly intravenous administration of Cilengitide (EMD 121974), a novel inhibitor of the integrins alphavbeta3 and alphavbeta5 in patients with advanced solid tumours. Eur J Cancer 2003, 39(7):917-926.

50. Dudley JT, Chen R, Butte AJ: Matching cancer genomes to established cell lines for personalized oncology. Pac Symp Biocomput 2011, 16:243-252.

51. Morgan AA, Khatri $P$, Jones RH, Sarwal MM, Butte AJ: Comparison of multiplex meta analysis techniques for understanding the acute rejection of solid organ transplants. BMC Bioinforma 2010, 11(9):S6.

52. de Sousa AR, Penalva LO, Marcotte EM, Vogel C: Global signatures of protein and mRNA expression levels. Mol Biosyst 2009, 5(12):1512-1526.

53. Greenbaum D, Colangelo C, Williams K, Gerstein M: Comparing protein abundance and mRNA expression levels on a genomic scale. Genome Biol 2003, 4(9):117.

54. Schwanhausser B, Busse D, Li N, Dittmar G, Schuchhardt J, Wolf J, Chen W, Selbach M: Global quantification of mammalian gene expression control. Nature 2011, 473(7347):337-342.

55. Vogel C, Abreu Rde S, Ko D, Le SY, Shapiro BA, Burns SC, Sandhu D, Boutz DR, Marcotte EM, Penalva LO: Sequence signatures and mRNA concentration can explain two-thirds of protein abundance variation in a human cell line. Mol Syst Biol 2010, 6:400.
56. Johnson WE, Li C, Rabinovic A: Adjusting batch effects in microarray expression data using empirical Bayes methods. Biostatistics 2007 $8(1): 118-127$.

57. de Jonge J, Kurian S, Shaked A, Reddy KR, Hancock W, Salomon DR, Olthoff KM: Unique early gene expression patterns in human adult-to-adult living donor liver grafts compared to deceased donor grafts. Am J Transplant 2009, 9(4):758-772.

doi:10.1186/1471-2164-14-275

Cite this article as: Dosanjh et al:: Genomic meta-analysis of growth factor and integrin pathways in chronic kidney transplant injury. BMC Genomics 2013 14:275.

\section{Submit your next manuscript to BioMed Central and take full advantage of:}

- Convenient online submission

- Thorough peer review

- No space constraints or color figure charges

- Immediate publication on acceptance

- Inclusion in PubMed, CAS, Scopus and Google Scholar

- Research which is freely available for redistribution

Submit your manuscript at www.biomedcentral.com/submit
C) Biomed Central 